\title{
Val M. Runge, Wolfgang R. Nitz, Johannes T. Heverhagen: the physics of clinical MR taught through images
}

\author{
Thieme, New York Stuttgart Delhi Rio de Janeiro, 2018, 318 p., format $15 \times 23 \times 1.5 \mathrm{~cm}$, ISBN \\ 978-1-62623-427-7, elSBN 978-1-62623-428-4
}

\section{Bruno Grignon ${ }^{1}$}

Received: 29 August 2018 / Accepted: 6 September 2018 / Published online: 14 September 2018

c) Springer-Verlag France SAS, part of Springer Nature 2018

Today, magnetic resonance (MR) imaging stands as a major diagnostic radiology technique, with a perpetual challenge: connecting clinical professionals with ever-advancing tools developed by MR scientists, and vice versa. To teach through images a practical approach to MR physics and imaging quality is the aim of this handy manual.

This visual book is divided into eight sections, subsequently devoted to: hardware, basic imaging physics, basic imaging acquisition, advanced imaging acquisition, flow, tissue-specific techniques, artifacts, and technologic innovations. Finally, a very useful appendix offers a handy list of the main acronyms used by the major MR equipment vendors.

Each section is composed of concise chapters dealing with an important point relevant to clinical MR, systematically presented on two pages, separately numbered (140 chapters in all), and referred to by an additional index at the end of the book, allowing a very quick and practical access. The topics covered encompass the breadth of the field, as well as discussion of the latest hardware and software innovations (such as MR PET, interventional MR, and 4D flow, among others).

In keeping with the title, this work provides more than 700 illustrations, composed of clinical images, anatomical drawings, histologic correlations, charts, and diagrams including in particular pulse sequencing and magnetization curves.
This book is the fourth edition of a first version published in 2005. Regarding the authors, Val M. Runge, and Johannes T. Heverhagen, respectively, Practicing Radiologist and Editor-in-Chief of Investigative Radiology, and Professor and Director, work both in the University Institute of Diagnostic, Interventional, and Paediatric Radiology Inselspital, University Hospital, Bern, Switzerland; Wolfgang R. Nitz is Assistant Professor of Experimental Radiology, University Hospital of Regensburg, Regensburg, Germany, and Senior Patent Manager, Siemens GmbH, Erlangen, Germany. An international panel of seven German, Swiss, American, and Canadian contributors has collaborated in writing this book.

Richly illustrated, concise, up-to-date, and easy-to-use, this handbook is an interesting tool for learning, leveraging, or mastering the capabilities of MR. As a result, it may be of great interest for all physicians and technologists dealing with MR.

Author contributions BG: manuscript writing and editing.

\section{Compliance with ethical standards}

Conflict of interest The author declares that he has no conflict of interest.
Bruno Grignon

b.grignon@chu-nancy.fr

1 University of Lorraine, CHU Nancy, Nancy, France 